\title{
6 PEDAGOGICA
}

No. 4 - ENERO/DICIFMBRE DE 2003

\section{$\frac{2}{2}$}
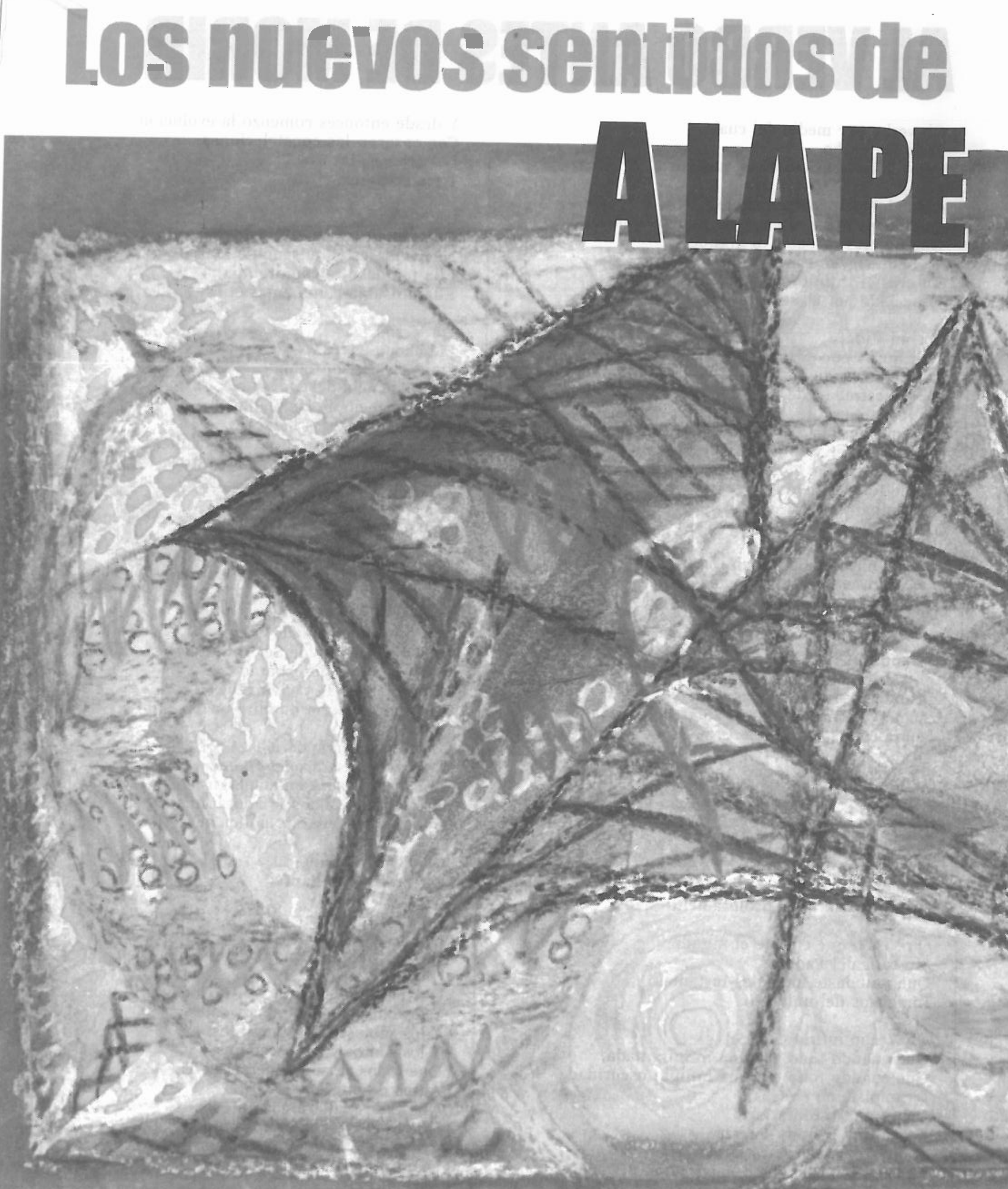


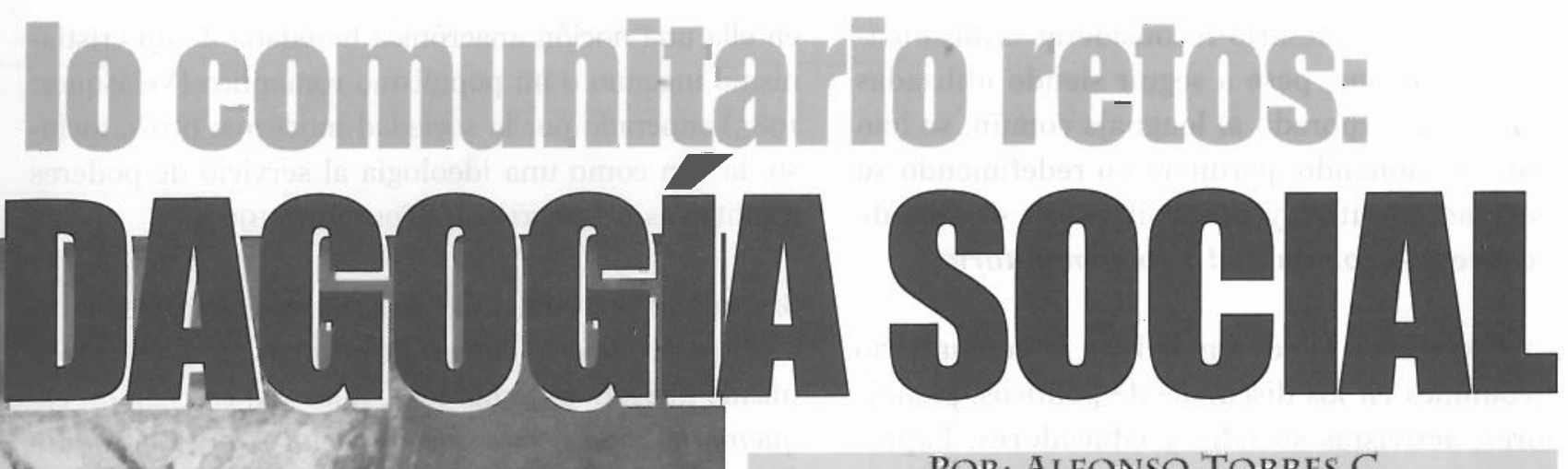

Docente del Departamento de Ciencias Sociales de la Universidad Pedagógica Nacional.

ste artículo presenta los conceptos expresados por el autor en su conferencia ante estudiantes y profesores de la Facultad de Educación de la Universidad Minuto de Dios el 26 de abril de 2002. En ella argumentó la vigencia de lo comunitario como noción que permite describir, analizar y encausar ciertas relaciones y dinámicas sociales contemporáneas. En un contexto de fragmentación de la vida social, de levedad en las relaciones personales, de individualización y homogeneización cultural, aparece como legítimo restablecer el vínculo social y reivindicar valores como la solidaridad y lo colectivo.

\section{LA COMUNIDAD: DE IMAGEN A CONCEPTO}

Nos encontramos en un periodo de crisis y agotamiento de las seguridades que en otros tiempos nos sirvieron para interpretar e intervenir la vida social. Teorías, métodos de investigación, políticas sociales y culturales no logran dar cuenta ni encausar eficazmente procesos y realidades que otrora eran pensados o conducidos fácilmente. La crisis de las ciencias sociales y el desmonte del Estado de Bienestar, junto a los vertiginosos cambios asociados a la globalización y la expansión mundial del capitalismo, así como el descrédito de las utopías que buscaron superarlo, han puesto en sospecha las certidumbres que predominaron durante décadas.

La efervescente complejidad de lo social siempre desborda los ordenamientos que los Estados y las ciencias sociales han creado para explicarlo y controlar- 
lo. Por ello es necesario reconsiderar críticamente categorías que, pese a seguir siendo utilizadas y haberse incorporado al lenguaje común, se han venido erosionando, perdiendo o redefiniendo su capacidad analítica y propositiva. Es el caso de los conceptos comunidad y lo comunitario.

Las referencias a la comunidad y a lo comunitario son comunes en los discursos de políticos, planificadores, activistas sociales y educadores. Expresiones como "comunidad universitaria", "comunidad escolar", "comunidades científicas" y "comunidad mundial" dejan ver la laxitud con que se usa esa palabra; más que un concepto, comunidad se ha convertido en una imagen que oculta más que lo que permite ver, pues tiende a identificarse con formas unitarias y homogéneas de vida social en las que prevalecen intereses y fines comunes. en ella una noción anacrónica heredada de un cristianismo ingenuo o un populismo romántico (Velásquez: 1985) superado por la sociedad moderna; otros, incluso, la ven como una ideología al servicio de poderes totalitarios o integristas. (Touraine: 1997).

Sin que lo pretendan, las posiciones entusiastas y escépticas frente a lo comunitario están atrapadas de la misma imagen de comunidad, pues ven en ella, un "esquema de vida o interacción social propio de aquellos grupos tradicionales en los cuales se consideran que las relaciones entre sus miembros pueden desarrollarse con mayor intensidad y compromiso afectivo" (Jaramillo: 1987); por ello, automáticamente asocian lo comunitario a lo rural, a lo popular, a lo local, realidades vistas como esencias unitarias y homogéneas propias del pasado.

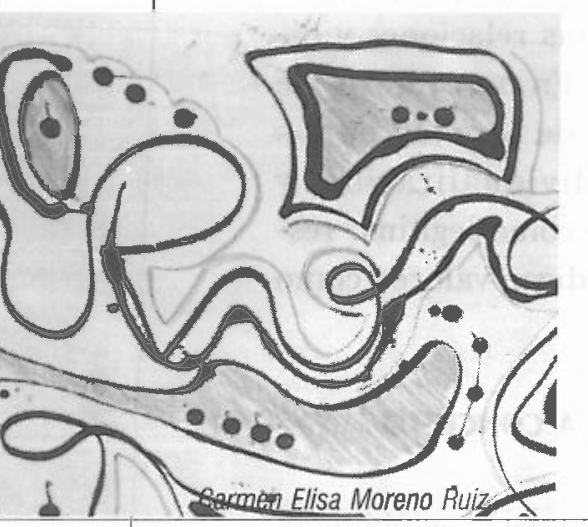

MÁS QUE UN CONCEPTO, COMUNIDAD SE HA CONVERTIDO EN UNA IMAGEN QUE OCULTA MÁs QUE LO QUE PERMITE VER
Sin embargo, desde finales del siglo $\mathrm{XX}$ es común encontrar en la literatura sociológica y política reivindicaciones a lo comunitario como concepto explicativo de procesos y vínculos sociales emergentes en el seno de las sociedades modernas, globalizadas (Hierneaux: 1999) y postmodernas (Maffesoli: 1990); así mismo, lo comunitario aparece como un valor e ideal políticos reivindicados por los nuevos movimientos sociales que se oponen a las consecuencias adversas y perversas que la modernización capitalista genera a lo largo y ancho del planeta. Por otra parte, a menudo muchas experiencias organizativas populares y movimientos sociales se reconocen como "comunitarios", en contraposición y resistencia a otras formas de acción y asociación subordinadas a la lógica del poder o del mercado.

Cabe entonces preguntarse si lo comunitario tiene vigencia como categoría analítica e ideal ético-político, en los albores del nuevo siglo, șin quedar atrapado en las imágenes idílicas, integristas o negativistas que prevalecen en el sentido común. Reivindicar la comunidad como categoría teórica y propositiva para interpretar y encauzar ciertas rela-
Por ello, la expresión comunidad genera reacciones encontradas: para unos despierta entusiasmo y simpatía al evocar idílicos esquemas de vida local unitaria; para otros, genera sospecha y escepticismo al ver 
ciones, prácticas, modos de vida contemporáneos que podríamos considerar como "comunitarias", exige tomar distancia con tales representaciones. Obliga más bien a revisar críticamente el lugar que ha ocupado esta noción en los intentos hechos desde las ciencias sociales para comprender la pervivencia y conformación de vínculos, identidades y proyectos sociales diferentes o alternos a la sociedad capitalista.

El presente artículo pretende mostrar cómo, dentro de los desarrollos, límites y consecuencias de la modernidad capitalista mundializada, han venido cobrando fuerza relaciones, modos de existencia y sentidos de pertenencia que podríamos considerar comunitarios; así mismo, destacar la emergencia de discursos y proyectos intencionales que reivindican y gene-

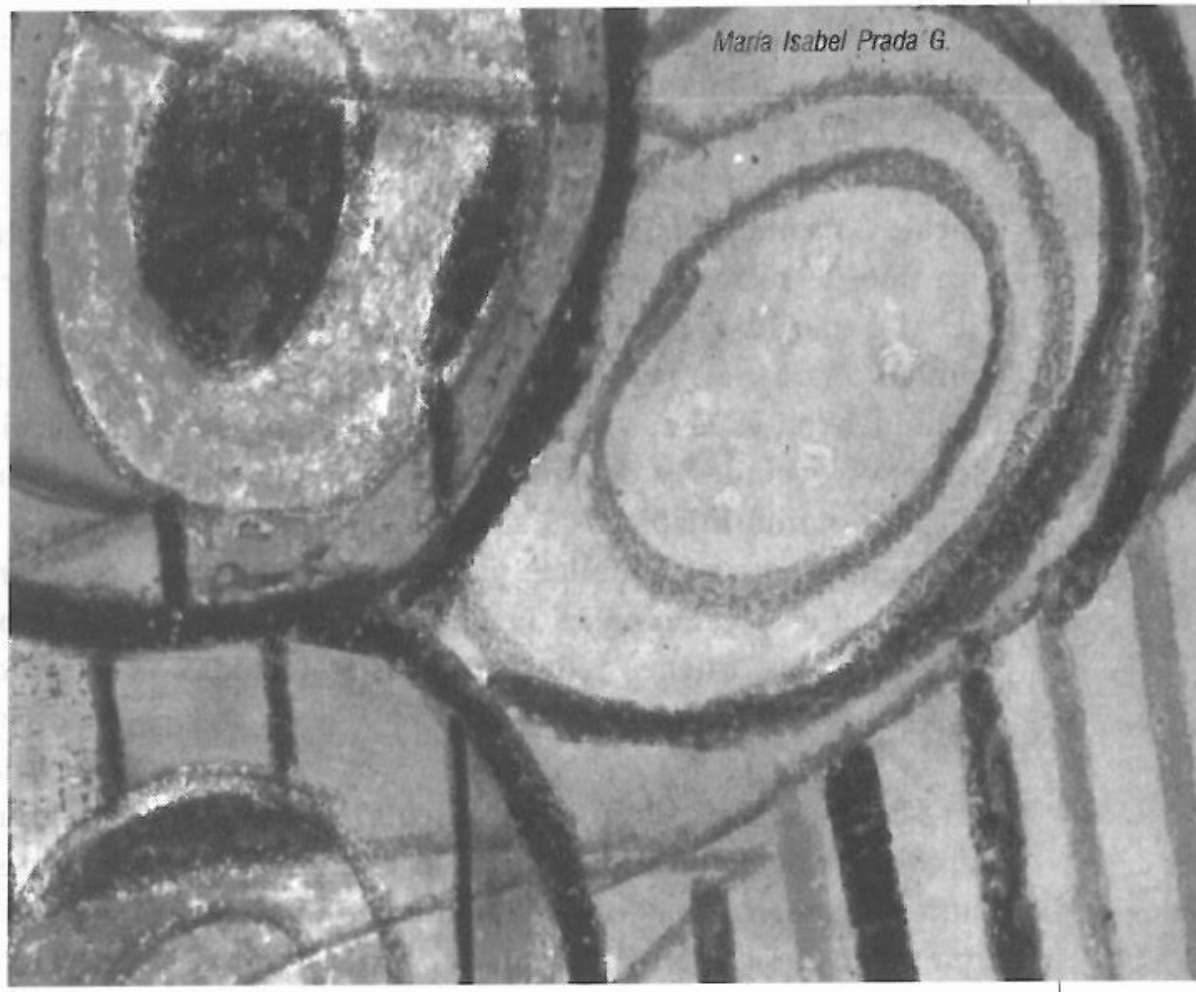
ran valores, vínculos de solidaridad, sentidos de pertenencia y visiones de futuro de carácter comunitario. Es decir, a nuestro juicio, es posible reivindicar la comunidad como una categoría analítica y propositiva capaz de describir, comprender y encauzar estos lazos sociales, esquemas de vida, referentes de identidad y alternativas sociales.

Construir un concepto crítico de comunidad que cumpla este cometido exige, en primer lugar, remitirnos a la tradición sociológica donde se asumió dicha noción como categoría descriptiva, tipología y como valor social con referencia a ciertos esquemas de vida e interacción en la sociedad desarrolladas con mayor intensidad y compromiso afectivos (Jaramillo: 1987, 53); o, en términos de Robert Nisbet $(1996,71)$, “todas las formas de relación caracterizadas por un alto grado de intimidad personal, profundidad emocional, compromiso moral, cohesión social y continuidad en el tiempo".

\section{LO COMUNITARIO EN LA TRADICIÓN SOCIOLÓGICA}

Como lo señala Nisbet (1996), en el contexto de los rápidos y radicales cambios que introdujeron las

revoluciones francesa e industrial, uno de los debates constitutivos de la sociología fue el referido a la comunidad, ya fuese como realidad empírica, como concepto o como valor social; lo comunitario se diferenciaba y se oponía a los nuevos vínculos y valores que la vida urbana moderna y la economía capitalista impusieron desde su generalización en el siglo XIX.

Mientras en las sociedades tradicionales la vida colectiva se articulaba en torno a lazos afectivos basados en el parentesco, la proximidad territorial, la identidad étnica o la afinidad de sus convicciones, en las ciudades modernas y el mundo de los negocios la relación social es abstracta: se sustenta en contratos entre individuos, en acuerdos de intereses basados en la utilidad. Pensadores con posiciones ideológicas tan disímiles como Marx, Proudhon y Comte, coincidieron en reconocer que la expansión de la modernidad capitalista, a la vez que desarticulaba los vínculos y valores comunitarios, necesariamente imponía su racionalidad en las demás esferas de la vida colectiva.

En este contexto, el joven sociólogo alemán Ferdinand Tönnies $(1887,1931)$ introdujo el empleo de la 
noción de comunidad como categoría analítica en su libro "Comunidad y sociedad", ambos conceptos entendidos como formas "típicas" de relación social y no como esencias o realidades empíricas. Lo comunitario (gemeinschaft) se refiere a un tipo de relación social basado en nexos subjetivos fuertes como los sentimientos, la proximidad territorial, las creencias y las tradiciones comunes, tal es el caso de los vínculos de parentesco, de vecindad y de amistad; en lo comunitario predomina lo colectivo sobre lo individual y lo íntimo frente a lo público; para Tönnies el prototipo de esta relación es la familia, pero también están las órdenes religiosas y las fraternidades de artes.

Por su parte, la expresión "gesellschaft" (traducida como asociación o sociedad, en el sentido de empresa comercial) es considerada como una relación social caracterizada por un alto grado de individualidad, impersonalidad, contractualismo que procede del mero interés y no de los fuertes estados subjetivos que implican los lazos comunitarios; la esencia de la gesellschaft es la racionalidad y el cálculo, por eso la empresa económica y la trama de normas e instituciones del Estado moderno son los mejores ejemplos de «sociedad». En fin, el advenimiento y expansión de la racionalidad moderna y capitalista serían el paradigma del modo de relación señalado.

La diferencia fundamental entre gemeinschaft y gesellschaft se sintetiza en que en aquélla los seres humanos "permanecen esencialmente unidos a pesar de todos los factores disociantes", mientras en ésta, "están esencialmente separados a pesar de todos los factores unificadores" (Nisbet: 1996, 106). Pero dado su carácter de tipos ideales, para Tönnies lo comunitario y lo societario no son inherentes a una época o colectivo social determinado; en consecuencia, vínculos comunitarios y societarios tampoco son excluyentes empíricamente.

Los planteamientos de Tönnies sobre comunidad fueron retomados por Max Weber; para este sociólogo alemán, ésa es una relación en la cual la actitud dẹ la acción social se inspira en el sentimiento subjetivo de los partícipes en la constitución de un todo; los vínculos comunitarios también generan un sentido de pertenencia basado en "toda suerte de fundamentos afectivos, emotivos y tradicionales". (Weber: 1977, 33).

Sin embargo, no toda participación en común de determinadas cualidades de la situación o de la conducta implica comunidad; el habitar en un mismo lugar o pertenecer a la misma etnia no conlleva necesariamente la presencia de vínculos o sentimientos subjetivos de pertenencia colectiva. Así, por ejemplo, la comunidad vecinal urbana supera las restricciones de las comunidades domésticas rurales en la medida en que permite más libertad a sus integrantes y posibilita desplegar "acciones comunitarias" en momentos de necesidad, emergencia o peligro; es lo que Weber llamó "la ayuda de la vecindad". (1944, 291).

A diferencia de los clásicos europeos, los sociólogos de la Escuela de Chicago, desde una perspectiva ecológica, retomaron el concepto de comunidad, para referirlo a áreas de la ciudad que constituían mundos sociales y culturales diferenciados; el papel de los sociólogos sería el de estudiar dichas unidades espaciales (vistas como comunidades), tales como los vecindarios populares, para reconocer los rasgos que les dan unidad e identidad. Los funcionalistas asumieron lo comunitario en el mismo sentido que la escuela ecológica; así, para Parsons (Citado por Neils: 1985,45$)$ "una comunidad es la colectividad cuyos miembros participan de una región territorial común como base de sus operaciones $y$ actividades diarias".

Desde presupuestos comunes y bajo la influencia de Simmel, Louis Wirth (1938) planteó que la vida urbana moderna impacta negativamente los lazos comunitarios y los sustituye por vínculos impersonales, fríos y fragmentados; tal mirada pesimista también es compartida por pensadores como Richard Sennet (1978) para quien el advenimiento del capitalismo moderno, al priorizar lo privado sobre lo público, afianzó los valores individualistas del 
habitante de la ciudad, y lo llevó a refugiarse en el ámbito familiar y vecinal.

A pesar de que otros autores como Oscar Lewis (Los hijos de Sánchez) refutaron estos planteamientos al demostrar que la convivencia urbana no siempre disolvía los estilos de vida comunitarios ni los restringía al espacio vecinal, los estudios norteamericanos de sociología de la ciudad no superaron el marco territorial para asumir lo comunitario ni la visión sólo desde la tensión entre lo tradicional y lo moderno. (Panfichi: 1996).

La influencia de la Escuela de Chicago trascendió los marcos sociológicos y llegó hasta la definición de las políticas públicas y programas de intervención con poblaciones populares, en el contexto de los programas desarrollistas que se impusieron en América Latina desde los años 50 del siglo XX. Incluso, en la actualidad se siguen empleando' las expresiones "comunidad", "integración comunitaria", "desarrollo comunitario" y "participación comunitaria" para referirse a poblaciones ubicadas en un mismo territorio (aldeas, barrios, localidades).

Esta perspectiva ecológica de comunidad dominó la sociología urbana y rural desde los años veinte hasta los sesenta, década en la cual corrientes teóricas como el marxismo introdujeron otros factores -estructurales, sociales y culturales- en el análisis de la vida citadina. Sin embargo, se generó cierto consenso entre los sociólogos (tanto funcionalistas como marxistas) en torno a la idea de que el avance del capitalismo y de la racionalidad moderna disolverían irreversiblemente los lazos comunitarios al expandirse, en todos los ámbitos, la individualización, la masificación, el Estado y las relaciones contractuales.

Más aún, dicha tendencia se vio como deseable por parte de las diferentes posiciones, pues lo comunitario -asociado a lo tradicional y premoderno- era considerado como un lastre para el progreso y el desarrollo histórico, ya fueran éstos identificados con el mercado, con el Estado o con el socialismo. No obstante, en el actual contexto de hegemonía de la globalización neoliberal, parece que lo comunitario vuelve a aparecer como un valor que persiste y se reactiva, incomodando al nuevo orden.

\section{LAS PARADÓJICAS CONSECUENCIAS DE LA GLOBALIZACIÓN CAPITALISTA}

Al llegar al siglo XXI, la promesa de progreso, bienestar y felicidad anunciada por el proyecto moderno (capitalista o socialista) no se cumplió. Sus frutos no han sido el progreso, el bienestar y la libertad sin límites que prometió, sino, como en la obra de Goya, la opresión, la desigualdad, la injusticia, la violencia, la homogeneización cultural y la destrucción ecológica. La economía dineraria ha impuesto su lógica mercantil de costo-beneficio empobreciendo a otras esferas de la vida social como el arte, la educación, la religión y el deporte.

El triunfo de la razón moderna no significó la emancipación del sujeto, sino la aniquilación de su subjetividad, de sus relaciones con otros y el deterioro de su entorno; encarnó la masificación de la vida de muchos, correlativa a su individuación, así como también la fragmentación y el aislamiento social, debilitando la posibilidad de emergencia de fuerzas sociales que impugnen el modelo económico y cultural predominante a nivel mundial. En lugar de individuos libres o autónomos, la modernidad capitalista reduce la individualidad casi exclusivamente al ámbito del trabajo que desempeña (rol) y al consumo que practica.

A diferenciä de lo que proclaman sus defensores, la globalización económica bajo la hegemonía del mercado no ha significado una superación de los efectos nocivos del capitalismo, sino su universalización. La mundialización económica y cultural, resultado de la revolución tecnológica en la electrónica, la informática y las comunicaciones, al estar subordinada a la lógica del capital, ha acelerado los procesos de concentración capitalista y profundizado las diferencias entre ricos y pobres. En la actualidad, las 225 familias más ricas del planeta poseen el equivalente al $40 \%$ de la población más pobre del mundo, más que el PIB de los 48 países más pobres. El capital de 
los 100 hombres más ricos del mundo era, en 1998, según la Revista Forbes, de 380.000 millones de dólares y el empresario que encabeza la lista, Bill Gates, gana un promedio de 2 millones de dólares por hora.

Para América Latina, la globalización subordinada al neoliberalismo ha acentuado el divorcio entre lo económico y lo social; en todos los países busca eliminar todas aquellos factores que obstaculizan la acumulación de ganancia, flexibiliza derechos sociales y económicos, desmantela los sistemas estatales de seguridad social, privatiza los otrora "servicios sociales" como la salud, la educación y los servicios públicos; además, desarticula las fuerzas sindicales y sociales que puedan oponérsele. Todo ello, a nombre del mercado y la democracia, cuando no de la civilización occidental.

Para no ir más lejos, en Colombia, a partir de la última década del siglo pasado, aumentaron los niveles de pobreza por encima del 50\% y, al comenzar el siglo XXI, llegan al 75\%; para no hablar del desempleo que en el año 2000 alcanzó la cifra record del $22 \%$ y eso sin considerar sus formas disfrazadas como el subempleo y la informalidad. A esta situación se suman la creciente concentración del ingreso, la exclusión y la violencia, los cuales están haciendo mella en el tejido social: más de 2 millones de desplazados en los últimos años y 30.000 homicidios por año también menoscaban la vida colectiva, incrementan el conflicto social y deterioran los lazos de solidaridad colectiva.

A esos indicadores sociales que hablan por sí solos de los efectos de la globalización neoliberal, hay que sumarle sus consecuencias en el plano subjetivo, pues ésta lleva al extremo los valores propios de la mentalidad capitalista: individualismo, competitividad, eficientismo, desbordado ánimo de lucro, mercantilización de todos los planos de la vida; la racionalidad del mercado se ha erigido como paradigma organizacional, ético y metodológico; se generaliza el conformismo, la apatía por lo público y la exaltación de la realización individual, del mismo modo que se hacen más leves los lazos cotidianos; hay regocijo por el encuentro efímero, se eluden compromisos, se sospecha de vínculos estables... (Hopenhayn: 1994).

La mercantilización generalizada de las relaciones sociales, llevada al extremo en el actual contexto neoliberal, busca disolver "toda forma de sociabilidad y la posibilidad de producir libremente otras formas de vida que representan la confirmación recíproca de la individualidad y de la opción de asignarse fines comunes" (Barcelona: 1999). Es decir, la hegemonía de un "pensamiento único", como lo pretenden algunos corifeos del neoliberalismo, también significa la imposibilidad de que surjan sujetos y subjetividades colectivas portadores de otros proyectos económicos, sociales, políticos y culturales alternativos al orden capitalista.

Pero, paradójicamente, junto a este empobrecimiento intencional de las relaciones sociales y de las subjetividades individual y colectiva, la expansión de la dominación capitalista a nivel mundial ha evidenciado, reactivado y posibilitado el surgimiento de modos de vida, valores, procesos, vínculos, redes y proyectos sociales que se salen de la lógica individualista, competitiva y fragmentadora del capitalismo. Estas dinámicas, no totalmente controladas por la globalización capitalista, están relacionadas con la recomposición de los tejidos sociales, hay emergencia de nuevas sociabilidades, asociaciones y movimientos sociales, así como de nuevos modos de entender lo público y la democracia que reivindican lo comunitario; incluso, algunos de sus protagonistas demandan su identificación con lo comunitario como valor alternativo.

\section{VIEJOS Y NUEVOS MODOS DE SER COMUNITARIO}

El reconocimiento y potenciación de estos nuevos sentidos históricos de lo comunitario pueden dar aliento a propuestas y proyectos alternativos al empobrecimiento material y subjetivo que el modelo capitalista mundial impone hoy en todos los rincones del planeta. No estamos proponiendo una utopía esencialista y totalizadora; sólo, explorando los 
alcances de una perspectiva interpretativa que perfila lo comunitario como categoría para reconocer y encauzar ciertas dinámicas sociales y políticas potencialmente emancipadoras.

En primer lugar, a diferencia de lo que suponía la sociología de la modernización, no todos los vínculos y valores comunitarios tradicionales desaparecieron al paso de la modernización capitalista; por el contrario, en algunos casos se fortalecieron y reactivaron estos vínculos en resistencia a las consecuencias adversas de la lógica del mercado; es el caso de las sociedades indígenas y campesinas andinas y mesoamericanas para las cuales lo comunitario, más que un vínculo, constituye un modo de vida ancestral, sustentado en la existencia de una base territorial común, unas formas de producción, unas autoridades propias y un repertorio de costumbres y saberes comunitarios.

En la última década también se ha dado un proceso de reindianización en varios países de América Latina, mediante una reac-

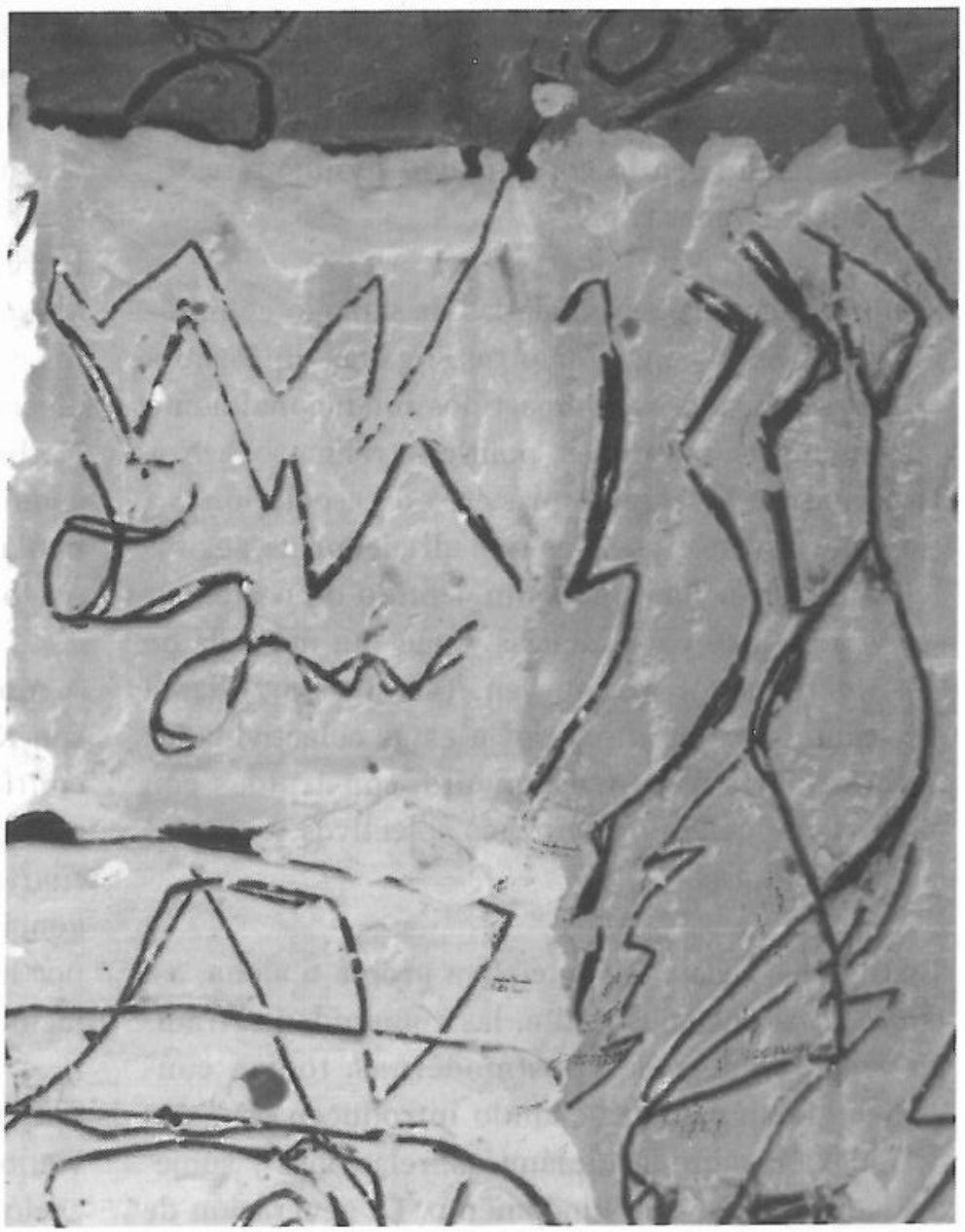
tivación intencional de las identidades ancestrales americanas y el desarrollo de estrategias de recuperación de territorios, costumbres y formas autóctonas de gobierno. Esto ha sido evidente en Colombia después de la promulgación de la Constitución Política de 1991 en la cual se reconoce el derecho de los indígenas a conformarse como comunidades (Gros: 2000); algo similar ocurre con las llamadas "comunidades afroamericanas".

También es el caso de las fases iniciales de los asentamientos urbano populares y de frentes de colonización rural, cuando las condiciones de vida adversa y el compartir un sistema de necesidades común, activan procesos de esfuerzo y ayuda mutua, así como vínculos estables de solidaridad basados en la vecindad y en otras redes de apoyo como el origen regional o la afinidad étnica (Torres: 1993). En las etapas iniciales de un asentamiento popular se conforma una malla de relaciones, solidaridades

y lealtades (tejido social) que se constituye en una fortaleza colectiva y en una defensa frente a las fuerzas centrífugas de la vida urbana o de los efectos de la pobreza y marginalidad. Procesos similares los hemos encontrado en coyunturas posteriores a un desastre natural como fueron los casos de México en 1985 y Armenia en 1999.

Por otro lado, en el contexto de las sociedades urbanas contemporáneas (Maffessolli, 1990), se están reactivando formas de sociabilidad marcadas por fuertes e intensos lazos afectivos en torno a espacios masivos o de consumo cultural, como lo muestran las diversas identificaciones juveniles (punkeros, rockeros, barras bravas). Maffessolli denomina a este tipo de vínculos (religare) efímeros pero intensos, propios de sociedades "postmodernas" de masas, como "comunidades emocionales", cuando retoma la categoría de Tonnies. Tales identidades se 
fundamentan en marcadas relaciones afectivas, no justificadas en una tradición sinơ en la vivencia estética presente, en la proxemia, en las redes existenciales, en la complicidad momentánea o en la ceremonia ritual.

Junto a las formas señaladas de vínculo comunitario, podemos agregar otras, ligadas en torno a intereses y valores compartidos intencionalmente (económicos, culturales, políticos, religiosos). Nos referimos a los nuevos procesos de asociación y a los movimiéntos sociales que alrededor de sus luchas e instituciones generan sentido de pertenencia e identidad comunitarias y que van más allá de los intereses que los mueven. Tarrow (1997) llama "comunidades de discurso" a estas colectividades intencionales o de pensamiento, construidas con base en la lucha por derechos colectivos y utopías emancipadoras.

En algunos casos, por iniciativa propia o ajena, así como en situaciones límite, las comunidades tradicionales, modernas o postmodernas, toman conciencia de su carácter cuando introducen espacios de reflexión sobre las dinámicas, relaciones y subjetividades que les dan fundamento. La generación de estos procesos reflexivos sobre los factores, rasgos y potencialidad que definen sus vínculos e identidades colectivas, configura lo que el investigador y pedagogo Stephen Kemmis (1993) denomina "comunidades críticas".

Este concepto, inicialmente acuñado para designar a grupos de docentes que se encuentran con el objetivo de deliberar sobre su práctica, puede extenderse a otras colectividades o asociaciones voluntarias y movimientos sociales que asuman reflexivamente su condición o ideales comunitarios. Tal reconocimiento e identificación con valores, vínculos y sentidos de pertenencia comunitarios, posibilita su fortalecimiento y capacidad de resistericia frente a modelos de vida y prelación social contrarios.

Junto a estas visiones de comunidad, vinculadas a dinámicas sociales particulares (territorializadas o no), cobra fuerza entre filósofos, políticos y politólogos, una idea de lo comunitario coligado a la reivindicación de lo público y lo democrático. Intelectuales como Hanna Arent y Pietro Barcelona retoman el significado de la expresión griega koinonia (lo común, frente a lo privado); otros, como Ivo Colo, recurren a la tradición cristiana sobre el «bien común», entendido como conjunto de asuntos comunes que hacen posible la convivencia entre diversos actores sociales; finalmente, autores como Norbert Lechner ven en la comunidad un espacio de condiciones y acuerdos mínimos que articula lo particular y lo diferente con lo general y común y que posibilita la viabilidad de la democracia.

A modo de conclusión provisional, consideramos con Kemmis (1993,7) que «los ideales comunitarios continúan dando una descripción significativa y apropiada de lo que podría constituir la vida colectiva». También que lo comunitario tiene plena vigencia descriptiva, interpretativa y propositiva en, por lo menos, las siguientes seis modalidades de relación y vida colectiva:

1. Comunidades tradicionales ancestrales, supervivientes o reconstruidas, que resisten a la modernización capitalista.

2. Comunidades territoriales construidas en condiciones de adversidad económica y social.

3. Comunidades emocionales no necesariamente territoriales.

4. Comunidades intencionales o de discurso, constituidas por asociaciones, redes y movimientos sociales alternativos.

\section{Comunidades críticas o reflexivas.}

6. Comunidades políticas o comunidades pluralistas.

A continuación retomaremos y profundizaremos sobre algunas de estas nociones contemporáneas de lo comunitario, ya sea como modo de existencia, como lazo social, como proyecto movilizador o como espacio político; en cada caso buscaremos recono- 
cer y vindicar su potencial emancipatorio frente al actual contexto de hegemonía neoliberal.

\section{LA RESISTENCIA DESDE EL TEJIDO SOCIAL COMUNITARIO}

Los dos primeros tipos de conformación de lo comunitario guardan estrecha relación por estar en un plano más social, específicamente en el plano del tejido social; su análisis nos permite comprender los modos actuales como se produce lo social, desde las sociabilidades elementales hasta las relaciones y conflictos sociales a nivel macro. La multiplicidad de esferas en torno a lo cual se produce y reproduce la sociedad (producción económica, mercado, consumo, territorio, reproducción biológica y simbólica, pareja, producción de conocimiento y manejo de información, etc.) nos lleva a reconocer la diversidad de espacios donde se teje la sociabilidad básica; las relaciones cara a cara, de proximidad, de solidaridad y reciprocidad no utilitaria se dan tanto en los territorios comúnmente construidos como en otros espacios como el parque, la plaza pública, las instituciones educativas, etc.

Son estas experiencias y relaciones cotidianas que tienen como eje un mismo espacio, institución social o actividad, las que conforman los tejidos sociales en torno a los cuales se generan las identidades comunitarias de primer tipo; desde tales tejidos se producen y reproducen los sistemas culturales y los saberes que dan sentido y racionalidad a las experiencias de sus actores, los cuales se diluyen, se fortalecen y se entrecruzan con otros sistemas simbólicos provenientes de distintos sectores. También es en relación con estas dinámicas como se conforma el tejido social básico que da identidad y fortaleza a los sectores subordinados y excluidos.

Nos referimos, por ejemplo, a experiencias comunes asumidas por las comunidades indígenas y campesinas ancestrales, o por frentes de colonización, o en una barriada popular. En el caso de indígenas y campesinos, el hecho de compartir durante muchas generaciones unos territorios, unas costumbres (fies- tas, tradiciones, celebraciones, etc.) y unas prácticas políticas comunes (formas de gobierno y de resolución de conflictos) hace de lo comunitario un modo de vida propio, una identidad y un valor que impele por su defensa. (Mattos: 1976).

También lo comunitario se vincula con la resistencia a los embates de la economía dineraria y de los poderes estatales que pretenden desarticular o disolver tales formas de vida tradicional y para convertir a sus miembros en mano de obra, consumidores y electores; la defensa de las tierras, lazos y valores comunitarios ha motivado diferentes levantamientos y rebeliones indígenas y campesinas en la historia colonial y republicana de América Latina; así lo muestran Enrique Florescano (1998) con los mayas y John Womack (2000) con el primer movimiento zapatista.

Esta reactivación de estrategias comunitarias de resistencia también se evidencia en el surgimiento actual de los movimientos indígenas en América Latina y en nuestro país; por ejemplo las rebeliones y levantamientos indígenas en Ecuador y Bolivia y el renacimiento de grupos étnicos que se consideraban extinguidos como el de los kankuamos en la Sierra Nevada de Santa Marta, los pastos en Nariño, los chimila en Magdalena y los muiscas en el altiplano cundiboyacense, así como la capacidad de resistencia pacífica de los indígenas colombianos a los actores armados.

En cuanto a las zonas de colonización, los asentamientos populares y cuando se presentan coyunturas posteriores a un desastre colectivo, las condiciones de precariedad a que es sometida una población, la «obliga» a actualizar o recrear formas sociales de cooperación y reciprocidad de carácter comunitario; esto lo hemos encontrado en la reconstrucción de las historias barriales bogotanas durante la segunda mitad del siglo XX, donde diferentes formas de ayuda mutua y acción comunal están presentes siempre en la vida de los asentamientos. (Torres: 1993). El hecho de que estas poblaciones se asumen a sí mismas como comunidades y ven en lo «comunitario» un valor de defensa y resistencia fren- 
te al Estado y otras fuerzas sociales, nos afirma la validez del concepto para referirse ellas.

\section{LO COMUNITARIO EN SITUACIONES DE BORDE}

En algunas situaciones "límite", originadas por una catástrofe o tragedia colectiva, como los terremotos de Ciudad de México en 1985 y Armenia en 1999, ante la magnitud de los problemas y frente a la inaplazable necesidad de resolver las adversidades, se activan vínculos de solidaridad y apoyo mutuo entre los afectados, más allá de las diferencias y distancias sociales y culturales previas al acontecimiento. Fue así como en los dos acontecimientos mencionados se formaron brigadas voluntarias para proteger los bienes de posibles saqueadores, para buscar a los desaparecidos o para preparar y compartir los alimentos.
Son situaciones donde se evidencia un vacío o insuficiencia institucional, los mecanismos de control se quedan cortos y emerge, por tanto, lo instituente, el magma efervescente de lo social; estos momentos de conmoción social y solidaridad son denominados por el antropólogo Victor Turner (1988) "comunitas", categoría que antepone a "estructura", lo instituido, lo ordenado; es lo que el sociólogo Francesco Alberoni (1988) llama "estado nascente" o momento creativo de la vida social, pero que el poder siempre buscará controlar, institucionalizar. En todo caso, lo comunitario es asumido por estos autores como posibilidad de reinvención de lo social, en su posibilidad emancipadora.

Por otra parte, para el sociólogo Michel Mafesolli (1990), las sociedades "postmodernas" de masas también son escenario de la emergencia de las lla-

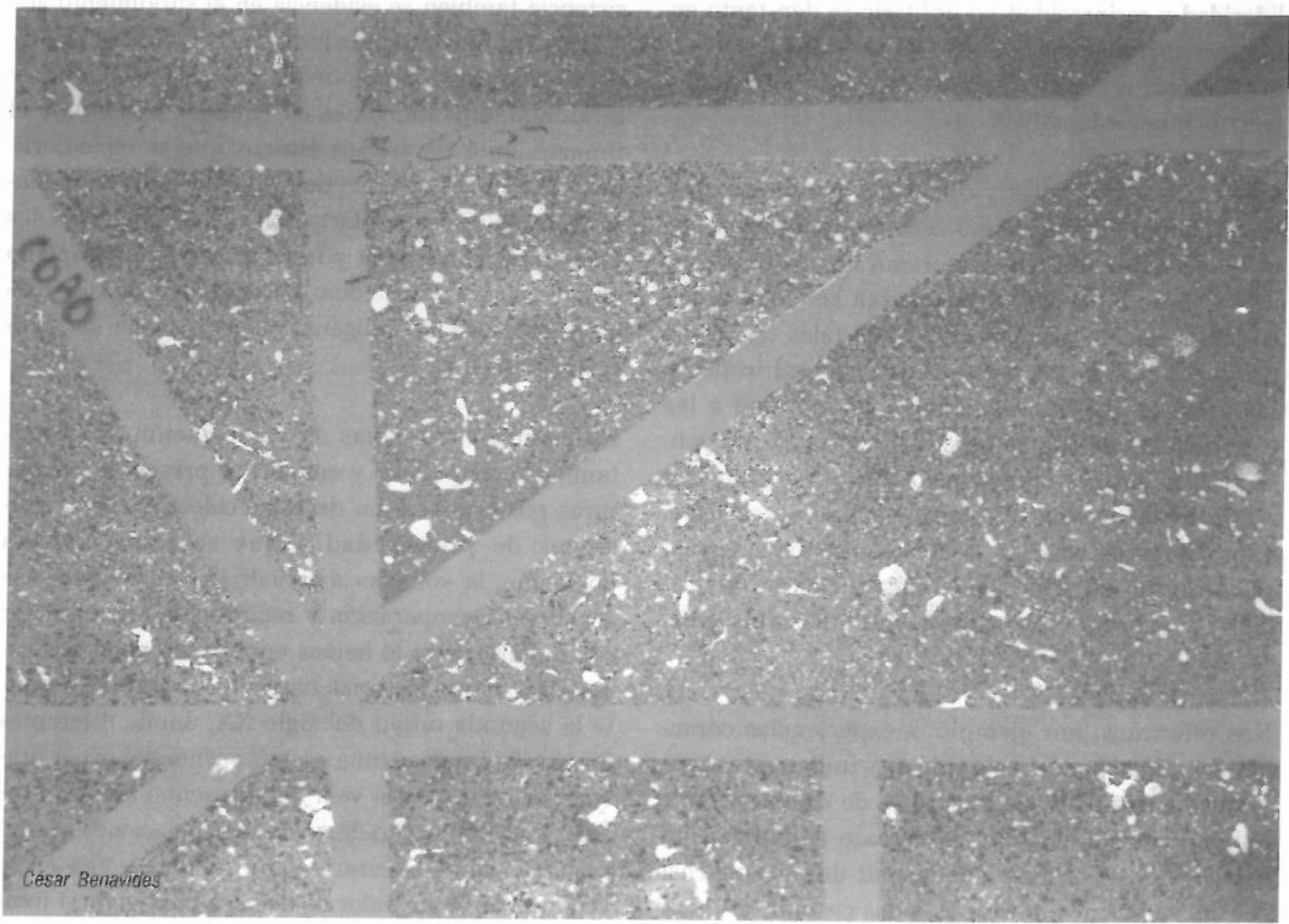


madas "comunidades emocionales" o "tribus", alrededor de las cuales se nuclean jóvenes y otras personas citadinas, quienes generan sus vínculos más fuertes en torno a "no lugares" como la calle, los centros deportivos, los centros comerciales y las discotecas, o en eventos como conciertos o partidos de fútbol; en estos espacios, la lógica de lo masivo activa sensibilidades, emociones y símbolos que remueven sentidos de pertenencia y vínculos efímeros pero intensos ("identificaciones"), inalcanzables en otros espacios de la vida urbana rutinaria signada por el anonimato, el individualismo y la soledad.

La preeminencia de vínculos y valores comunitarios en los espacios y coyunturas específicas de la vida social señalados, no significa que entre sus participantes no existan diferencias ni jerarquías internas. Como ya lo han evidenciado los antropólogos, sociólogos e historiadores, al interior de las sociedades tradicionales, de las comunidades territoriales y emocionales, las relaciones comunitarias no siempre se dan entre iguales, sino también entre jerarquías y dominación; del mismo modo, no son ajenas las diferenciaciones y tensiones internas, los cuales le imprimen dinamismo y complejidad a los esquemas relacionales, de vida y de pertenencia comunitarias.

\section{LAS ORGANIZACIONES $Y$ LOS MOVIMIENTOS SOCIALES RECONSTRUYEN LO COMUNITARIO}

Otros tipos de acción e identificación comunitaria van más allá del marco de lo tradicional, local o inmediato; se trata de las asociaciones y movimientos constituidos intencionalmente como defensa y alternativa a la dominación del capital y del Estado; allí no sólo convocan las necesidades o adversidades comunes, sino el propósito explícito de superarlas con la acción organizada y en función de unos valores compartidos. Hablamos, entonces, de comunidades intencionales que "surgen por la decisión de un grupo con el propósito deliberado de reorganizar su convivencia de acuerdo a normas y valores idealmente elaborados, en base a credos o a nuevos marcos sociales de referencia". (Calero: 1984, 14).
Dentro de tales comunidades de discurso consideramos a las generadas por las ya clásicas demandas económicas o en defensa de la propiedad, la producción y el consumo (por ejemplo los movimientos campesino, obrero y urbano-popular) y a las que son producidas por las nuevas tensiones e inconformidades que despliega la expansión capitalista en todas las esferas de la vida social. Algunos autores explican la incidencia de estos "nuevos movimientos sociales" en la construcción de nuevas comunidades de comunicación y sentido, por la colonización del mundo por parte de las lógicas económicas y del poder moderno; los nuevos conflictos surgen por la intersección entre sistema y mundo de la vida cotidiana:

La práctica de los movimientos alternativos se dirige contra la instrumentalización del trabajo profesional para fines de lucro, contra la movilización de la fuerza de trabajo por presiones del mercado, contra la compulsión a la competividad y el rendimiento [...]; también contra la monetarización de los servicios, de las relaciones y del tiempo, contra la redefinición consumista de los ámbitos de la vida privada y de los estilos de vida personal. (Habermas: $1987,560-561$ ).

Mientras en las comunidades tradicionales el referente subjetivo es la memoria colectiva, en las comunidades intencionales las necesidades son reelaboradas como derechos y reivindicaciones; entran en juego además los proyectos y visiones de futuro, así como las utopías, las ideologías y los valores compartidos. En las dinámicas asociativas, las redes y los movimientos sociales los situamos en el plano de los proyectos como conciencia de transformar lo deseable en posible y desplegar prácticas para lograrlo.

Para Joaquín Brunner $(1992,57)$ la expresión más novedosa de reagrupación comunitaria en la modernidad actual tiene lugar en la formación de «redes», entendidas como comunidades libremente definidas de individuos y grupos autónomos que operan en torno a bases de identificación más o menos abstractas. En éstas, al igual que en los nuevos movimientos sociales (también considerados como "redes en mo- 
vimiento"), «se afirma un substrato de identidad emocionalmente compartido, donde se rechazan jerarquías rígidas, se elaboran proyectos frente al mercado y el Estado y se rechazan el tecnocratismo y el neoliberalismo».

El hecho de tener comunes sentimientos de indignación frente a las injusticias contra las que se lucha, así como el compartir y construir convicciones, valores y utopías, hace que los participes de estas redes y movimientos se sientan partícipes de una hermandad que va más allá de las fronteras de los Estados; éste es el sentido de las siguientes palabras pronunciadas por el Premio Nobel José Saramago en el reciente homenaje a Ernesto Sábato: "Ernesto y yo somos hermanos. No nos une la sangre, sino una identidad común, una fraternidad por las ideas, la ilusión, el mundo y la gente". (El Tiempo: abr., 13, 2002).

Las comunidades intencionales se pueden convertir en «comunidades críticas» en la medida en que identifican «por medio de la reflexión deliberadora y la autorreflexión, algunas de las formas en que la cultura vigente opera en su intento por limitar la formación y el mantenimiento de comunidades»; por ejemplo, cómo la solidaridad y la fraternidad se ven minadas por las políticas o los intereses privados. Un proceso de reflexión crítica debe permitir conocer y asumir los factores externos y tensiones internas que dificultan la construcción de vínculos solidarios.

La construcción colectiva de un horizonte histórico, las experiencias acordadas y compartidas, así como la lucha contra otros actores con proyectos diversos, contribuyen a que estas constelaciones de individuos asociados intencionalmente se conviertan en actores colectivos autónomos, con proyectos propios y con capacidad de incidir en la dinámica social en su conjunto. Los sujetos colectivos se van constituyendo en la medida en que pueden generar una voluntad colectiva y despliegan un poder que les permite construir realidades con una direccionalidad consciente. (Zemelman: 1995).
La identidad colectiva en este nivel del análisis no es sólo racional, también está basada en vínculos afectivos y referentes simbólicos que se configuran a lo largo de las experiencias compartidas. Lo comunitario aquí no es un agregado de individuos o grupos sino un espacio de reconocimiento común. Finalmente, las experiencias comunitarias intencionales buscan acercarse y solidarizarse con grupos sociales «desheredados» por la modernización, cuyos derechos reclaman y cuya condición buscan transformar. Pero al mismo tiempo, buscan convertirlos y convertirse ellos mismos en fuerzas sociales con capacidad de incidir en las políticas públicas, en la orientación de las sociedades en su conjunto; podríamos afirmar entonces que los movimientos sociales son "comunidades de comunidades" que luchan por unos objetivos comunes y tienen capacidad de transformar las estructuras sociales.

Algunos ejemplos de «comunidades intencionales» en nuestro país son el movimiento indígena, el de las Comunidades Eclesiales de base, las redes de jóvenes, el asociacionismo femenino, las asociaciones de defensores de sus viviendas, los movimientos ambientalistas y las organizaciones de defensa de derechos humanos. Todos ellos han nacido como producto de luchas por demandas o de proyectos específicos; construyen discursos, instituciones y simbologías propias, en torno a los cuales crean relaciones solidarias y "de hermandad" entre sus militantes, así como sentidos de pertenencia colectiva y lazos subjetivos tanto racionales (ideológicos, valorativos) como emocionales.

\section{LO COMUNITARIO, BASE DE LO PÚBLICO Y DE LO DEMOCRÁTICO}

La crisis de legitimidad del Estado moderno y de sus instituciones típicas (parlamento, partidos políticos), así como el reconocimiento de la preeminencia de otros factores y actores en la definición de las políticas públicas (agencias financieras internacionales, trasnacionales, grupos de presión, movimientos sociales), han llevado a que los modos de hacer política y de representarla se estén redefiniendo en los últimos años. 


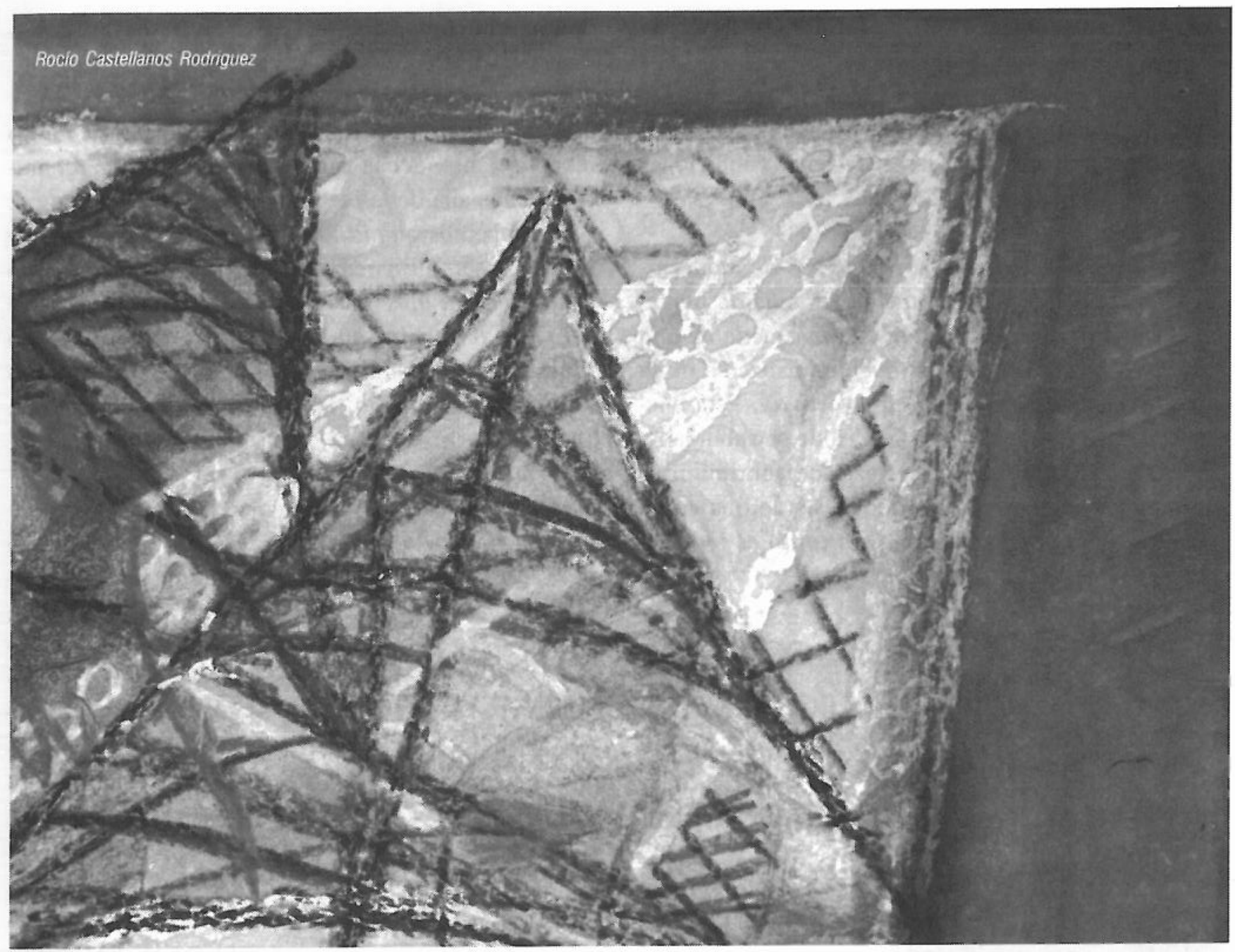

Autores como Touraine (1997), Guattari (1995) e Ivo Colo (1995) coinciden en que no deben ser el Estado ni el mercado los que rijan el futuro de las sociedades humanas y sus objetivos esenciales. Desde perspectivas diferentes reivindican la defensa de un espacio público en la sociedad, más allá de los intereses privados y estatales, alrededor del cual las colectividades sociales puedan construir lo común en el marco de lo diferente.

En un mundo donde cada vez son más ricas las diferencias culturales, se hace necesaria la creación de condiciones para su reconocimiento y legitimación, así como de unas reglas de juego básico que todos respeten. De este modo, entre los intereses particulares y el Estado, se abre la esfera de lo público, entendido como el lugar donde lo individual y lo particular se reconcilian con lo general y colectivo. Es decir, «la pregunta por los nexos entre los diversos proyectos de buen vivir, entre los distintos mundos morales que se presentan en sociedades complejas, como las actuales, y el ámbito público, el espacio en el que todos estos mundos confluyen y en el que se determina la estructura básica de la sociedad". (Colo: 1995).

En esa misma dirección, es necesario defender lo comunitario en la perspectiva del reconocimiento del sentido de pertenencia a una colectividad política, base social de la democracia, y de nombrar el espacio de «bien común» y la política que haga posible tal democracia. En el primer caso, Lechner $(1993,7)$ recuerda que «un elemento del credo democrático es la idea de comunidad en un sentido lato: pertenencia a un orden colectivo». Como las políticas de ajuste sólo han provocado una mayor segmentación 
social y exclusión de una proporción creciente de la población, tal aumento de injusticia y desigualdad ha llegado a un nivel tal que el orden político ha perdido legitimidad y se avivan los anhelos de comunidad, del deseo de tener condiciones básicas de solidaridad social.

De este modo, "los mismos procesos de modernización que rompen los antiguos lazos de pertenencia y arraigo, dan lugar a la búsqueda de una instancia que integre los diversos aspectos de la vida social en una identidad colectiva». Esta búsqueda se nutre de las necesidades de sociabilidad y seguridad, de amparo y certeza, de sentimientos compartidos, los cuales pueden ser leídos como «solidaridad postmoderna», «en tanto es más ex-

dę lo común y posibilita el desarrollo de lo individual y lo diferente.

Con estos planteamientos estamos frente a un nuevo modo de entender la comunidad política y la democracia más allá de la idea liberal de Estado moderno. «Hoy sabemos que la idea de comunidad no puede pensarse como espacio opresivo y autoritario, sino como elección libre buscada en la conciencia de que sólo en la reciprocidad de las relaciones no dinerarias se produce el verdadero reconocimiento de la diferencia y la particularidad». (Barcelona: 1992).

De la misma manera, una democracia en sentido comunitario puede ser entendida como «ese espacio de lo público donde surgen todas nuestras creencias sobre lo posible, pero además donde también éstas puedan ser reconocidas por todos los actores individuales $y$ sociales» (Zemelman: 1995, 29). Así, la democracia aparece como el sistema más idóneo para garantizar la vida pública, la cual cumple la

presiva de una comunión de sentimientos que de una articulación de intereses". (Lechner: 1993, 11).

Este deseo difuso pero intenso de comunidad es un rasgo sobresaliente de la cultura política en América Latina, pero no significa siempre un anhelo democrático. El miedo al conflicto y a la diferencia también puede canalizarse a través de propuestas autoritarias o populistas como lo hemos presenciado en varios países durante la actual coyuntura política. El reto es, entonces, cómo articular deseo de comunidad y democracia, búsqueda de integración y pluralidad, identidad y respeto a la diferencia. Para Lechner ello es posible en la medida en que se fortalezca lo público como esfera de reconocimiento recíproco; frente al mercado y la estatización, lo público permite el reconocimiento función de articular los planos de lo personal y de lo social, de tal suerte que lo propio de la vida personal y colectiva, así como lo que es constituido por lo social, no conformen compartimientos estancos sino mecanismos de comunicación, solidaridad y reciprocidad.

La disputa actual en el campo de la filosofía política entre liberales y comunitaristas, sobre la cual no me detendré, vuelve a traer a discusión esta tensión entre los fundamentos individuales y colectivos de la democracia y del derecho (Dwornkin: 1997; Mouffe: 1999). La posibilidad de construirla desde el reconocimiento de la pluralidad de comunidades, en el seno de una misma unidad política, ha llevado a que algunos autores reivindiquen nociones como la de comunidad pluralista o "communitas communi- 
tarum" (Nisbet: 1990) o la de "comunitarismos no excluyentes" (De la Peña: 1998) para referirse a sociedades o sistemas políticos democráticos que puedan contener y dar viabilidad a diferentes comunidades, sujetos y proyectos sociales y culturales, en torno a unos proyectos comunes y una reglas de juego respetadas por todos.

El contexto descrito hace necesario generar propuestas políticas alternativas que se salgan de su lógica hegemónica y requieran la democracia «como juego de proyectos político-ideológicos que conllevan distintas visiones de futuro, mediante los cuales los actores políticos y sociales definen el sentido de su quehacer, y por lo mismo, su propia justificación para llegar a tener presencia histórica». (Zemelman: 1995, 35).

Por tanto, la democracia debe posibilitar que las diversas potencialidades de los grupos sociales lleguen a plasmarse en proyectos viables. La vida de la democracia se asocia a la capacidad para potenciar el desenvolvimiento y expresión de diferentes grupos sociales y políticos a través de proyectos, si no divergentes, al menos no coincidentes.

Si somos consecuentes con estos nuevos sentidos de comunidad política, bien común y democracia, se abre paso un nuevo modo de asumir la política como «una orientación y una práctica que acompaña como servicio, a la producción de comunidad» (Gallardo: 1996, 27); es decir las prácticas, discursos e instituciones «que facilitan y potencian la constitución como comunidad de un conglomerado humano particular y diverso». (Ibíd.).

Lo comunitario como ideal de vida social

Reconocida la existencia de diversos modos de emergencia de. lo comunitario en la sociedad contemporánea y su potencial impugnador del orden económico, político y ético vigente, cabe preguntarse si es posible y deseable el impulso de proyectos sociales, culturales y educativos que reclamen como ideales de organización social los valores, vínculos y modos de vida comunitarios. Es decir, que plantee como deseable la generalización de identidades, virtudes, lazos, organizaciones y proyectos sociales basados en un alto grado de compromisos personales y morales y en valores altruistas como la solidaridad y el respeto a la diferencia, así como que fomenten la constitución de identidades y subjetividades colectivas y la cohesión social en torno a iniciativas y proyectos progresistas o emancipadores.

La respuesta puede ser afirmativa si reconocemos los desafíos que dichas dinámicas comunitarias y neocomunitarias le han planteado a la filosofía política, a la sociología y a la sicología social, así como a las prácticas de intervención, a la animación social, la educación popular y el desarrollo social. En cuanto a lo primero no me detendré, dado que dichos desafíos han orientado las argumentaciones precedentes; me centraré en las implicaciones dentro de ámbitos de acción práctica.

En primer lugar, las acciones de intervención social con poblaciones donde perviven relaciones de tipo comunitario y la expansión de experiencias asociativas y de movimientos en torno a temáticas que generan identidad comunitaria, han iniciado procesos y propuestas educativas y culturales ligadas a su especificidad; así, por ejemplo, hoy emergen discursos y prácticas educativas para indígenas, campesinos y desplazados por la violencia, al tiempo que educación ambiental, en derechos humanos y para el consumo.

En efecto, en casi todos estos procesos de acción e intervención social con comunidades tradicionales e intencionales, aparece, tarde que temprano, la necesidad de introducir un componente educativo que dinamice y anime la formación de los actores de base y los dirigentes en cada campo específico. Generalmente, una de sus dimensiones es la de construir y fortalecer el sentido de pertenencia y de identidad en torno a las relaciones y valores compartidos o deseados a través de la activación de la memoria colectiva y de otras propuestas que hacen visibles los valores y vínculos comunitarios que le han dado continuidad, identidad y fuerza a los procesos. 
Frente a la crisis de los grandes metarrelatos, discursos estructuralistas y prácticas estrategistas, las identidades y los valores comunitarios son cada vez más buscados y apreciados por grupos y asociaciones de base como las mujeres, los jóvenes, las minorías étnicas y los cristianos. Sin embargo, cuando este énfasis no va acompañado de otros procesos como la promoción individual y la participación democrática de sus integrantes, así como con el compromiso colectivo con el cambio social y la democratización de la sociedad en su conjunto, los grupos pueden caer en lo que Bengoa (1992) y Brunner (1992) consideran desviaciones "comunitaristas".

En segundo lugar, los procesos de construcción de democratización política, de ciudadanía y de formación de un sentido de lo público han incorporado acciones culturales y educativas explícitas para sensibilizar y formar a los sujetos de dichos proyectos. Incluso, en países como el nuestro, se han creado instituciones y programas desde el gobierno y la iniciativa privada para impulsar este tipo de formación política. De este modo, es cada yez más común encontrar propuestas educativas y pedagógicas para la democracia, para la ciudadanía, para la convivencia social, para la paz, etc.

En estos casos se asume, como condición necesaria para la construcción de una cultura y una sociedad democráticas, la preocupación por fortalecer sentidos de identidad comunitaria relacionados con esos valores,. Perro, también, si se destaca sólo la dimensión pública e institucional de la democracia, sin fomentar la conformación de sujetos colectivos y posibilidades para llenarla de sentido social y cultural, se puede quedar en el plano formal de comunidades políticas sin contenido.

En tercer lugar, la irrupción de estas nuevas dinámicas sociales, culturales y políticas le plantea a las instituciones escolares nuevas demandas: recuperar su lugar cultural en la formación para la democracia; contribuir a la educación ciudadana; colaborar en la formación en derechos humanos, formar en una cultura no sexista, etc. Se les exige que inyolucren en sus currículos las temáticas y problemáticas propias de la complejidad social descrita y de las singularidades de su contexto local o social; por ejemplo, que enfaticen la formación de identidad regional o étnica, así como en el respeto a la diferencia.

A mi juicio, en dicha intersección entre una educación para los procesos de afirmación o construcción de comunidades de sentido, culturales e intencionales, para la afirmación de procesos de identidad política global y el desplazamiento de la escuela hacia estos nuevos contextos sociales, es posible pensar en una dimensión educativa y pedagógica comunitaria. Una dimensión necesaria, porque contribuiría a fortalecer desarrollos de producción social de tipo comunitario y de construcción de identidades colectivas; pero no suficiente, dado que las demandas educativas hechas desde las experiencias y espacios señalados también involucran conocimientos y valores para el desempeño en el campo específico de acción (género, ambiente, juventud, etc.) y para la movilidad individual de sus participantes, así como para la transformación de la sociedad y la participación democrática dentro de ella.

\section{Bibliografía}

ALBERONI, Francesco. Movimiento e institución. Madrid: Editorial nacional, 1988. ANDERSON, Neils (1960). Sociologia de la comunidad urbana. México: Fondo de Cultura Económica, tercera reimpresión, 1985.

ARENDT, Hanna. La condición humana. Barcelona: Paidós, 1998.

BARCELONA, Pietro (1992). Postmodemidad y comunidad. El regreso de la vinculación social. Valladolid: Trota, tercera edición, 1999.

BRUNNER, José Joaquín. Cartografias de la modemidad. Santiago: Dolmen, 1995. COLO, ivo. "Ciudadania y sociedad postmodema". En: Revista Foro \# 26. Bogotá: 1995. DE IPOLA, Emilio. La crisis del lazo social. Durkheim, cien años después. Buenos Aires: Eudeba, 1998.

DE LA PENA, Guillermo. La modernidad comunitaria. México DF.: 1998. DELGADO, Manuel. El animal público. Barcelona: Anagrama, 1999. DWORKIN, Ronald. La comunidad liberal. Bogotá: $U$. de los Andes, 1996. FLORESCANO, Enrique. Etnia, estado y nación. México DF: Aguilar, 1998. GALLARDO, Helio. "Elementos de politica y antipolitica en América Latina". En: Pasos \# 65. San José de Costa Rica: DEl, 1996.

GROS, Christian. Politicas de identidad. Bogota: ICANH, 2000.

GUATTARI, Félix. Las tres ecologias. Barcelona: El navegante, 1995.

HABERMAS, Jurgen). Teoria de la acción comunicativa. Madrid: Taurus, 1987.

HÉUFR, Agnes. "Individuo y comunidad". En: Historia y vida cotidiana. Barcelona: Grijalbo, 1972

HÉULR, Herman. Ensayos sobre politica. Barcelona: Península, 1967. Teoria del Estado. México DF: FCE, 1979.

HIERNAUX, Daniel. Los senderos del cambio. México DF: Plaza y Valdés, 1999. 
HOPENHAYN, Martín). Niapocalipticos ni integrados. Santiago de Chile: Fondo de Cultura Económica, 1994.

JARAMILO, Jaime Eduardo. Tipologías polares, sociedad tradicional y campesinado. Bogota: Universidad Nacional, 1987.

KEMMIS, Stephen. "La formación del profesorado y la extensión de comunidades críticas". En: Investigación en la escuela \# 19. Madrid: 1993.

LECHNER, Nobert. "En büsqueda de la comunidad perdida". En : Revista Foro. Bogotá: 1993. MAFFESOW, Michel. El tiempo de las tribus. Barcelona: Ikaria, 1990.

MATTOS, José. Hacienda, comunidad y campesinado en el Peri. Lima: IEP, 1976.

MOUFFE, Chantal. El retorno de lo politico: comunidad, ciudadanía pluralismo, democracia

radical. Barcelona: Paidós, 1999.

NISBET, Robert. Os filosofos sociais. Brasilia: Editora Universidade de Brasilia, 1990.

1996

. La formación del pensamiento sociológico. Buenos Aires: Amorrortu Editores,

PANFICHI, Aldo. "Del vecindario a las redes sociales". En: Debates en Sociología \# 20-21.

Lima: Universidad Católica de Perú, 1996.

RODRIGUEZ, VILLASANTE Tomás. "Clientelas y emancipaciones: una introducción

metodológica". En : Las ciudades hablan. Caracas: Editorial Nueva Sociedad, 1994.

SENNET, Richard. El declive del hombre público. Barcelona: Peninsula, 1978.

SILVEIRA, Héctor. Identidades comunitarias y democracia. Madrid: Trotta, 2000.

TARROW, Sydney. El poder en movimiento. Madrid: Alianza, 1997.

TOONNIES, Ferdinand. Comunidady sociedad. Buenos Aires: Editorial Losada, 1947.

(1931). Principios de sociologia. México DF: Fondo de Cultura Económica,
"Nacimiento de mis conceptos de comunidad y sociedad". En:

Sociologica \# 1. México DF: UAM Azcapotzalco, 1989.

TORRES, Affonso. "Crisis de modemidad y nuevos sentidos de lo comunitario". En:

Revista Pedagogía y saberes \# 9. Bogotá: UPN, 1996.

TOURAINE, Avain. ¿Podremos vivir juntos? México: Fondo de Cultura Económica, 1997.

TURNER, Victor. El proceso ritual. Estructura y antiestnuctura. Madrid: Tauns, 1988.

VELÁZZUEZ, EnTique. "Comunidad: ¿una imagen o un concepto?" En: Procesos y

politicas sociales \# 22. Bogotá: 1985.

WEBER, Max. "Comunidad y sociedad". En: Economia y sociedad. México: FCE, 1944.

WIRTH, Louis. Urbanism as a way of life. USA: Chicago Press, 1938.

WOMACK, John. Zapata yla revolución mexicana. México: Siglo XXI América Nuestra,

1969.

ZEMELMAN, Hugo. "La democracia latinoamericana: iun orden justo y libre?». En:

Estudios Latinoamericanos. Año 2 \# 4. México DF: CELA UNAM, 1995.

- De la historia a la políica. México DF: UNAM-Universidad de las Naciones Unidas, 1996.

1998

Pie de página

1 Docente del Departamento de Ciencias Sociales de la Universidad Pedagógica Nacional. 1987.

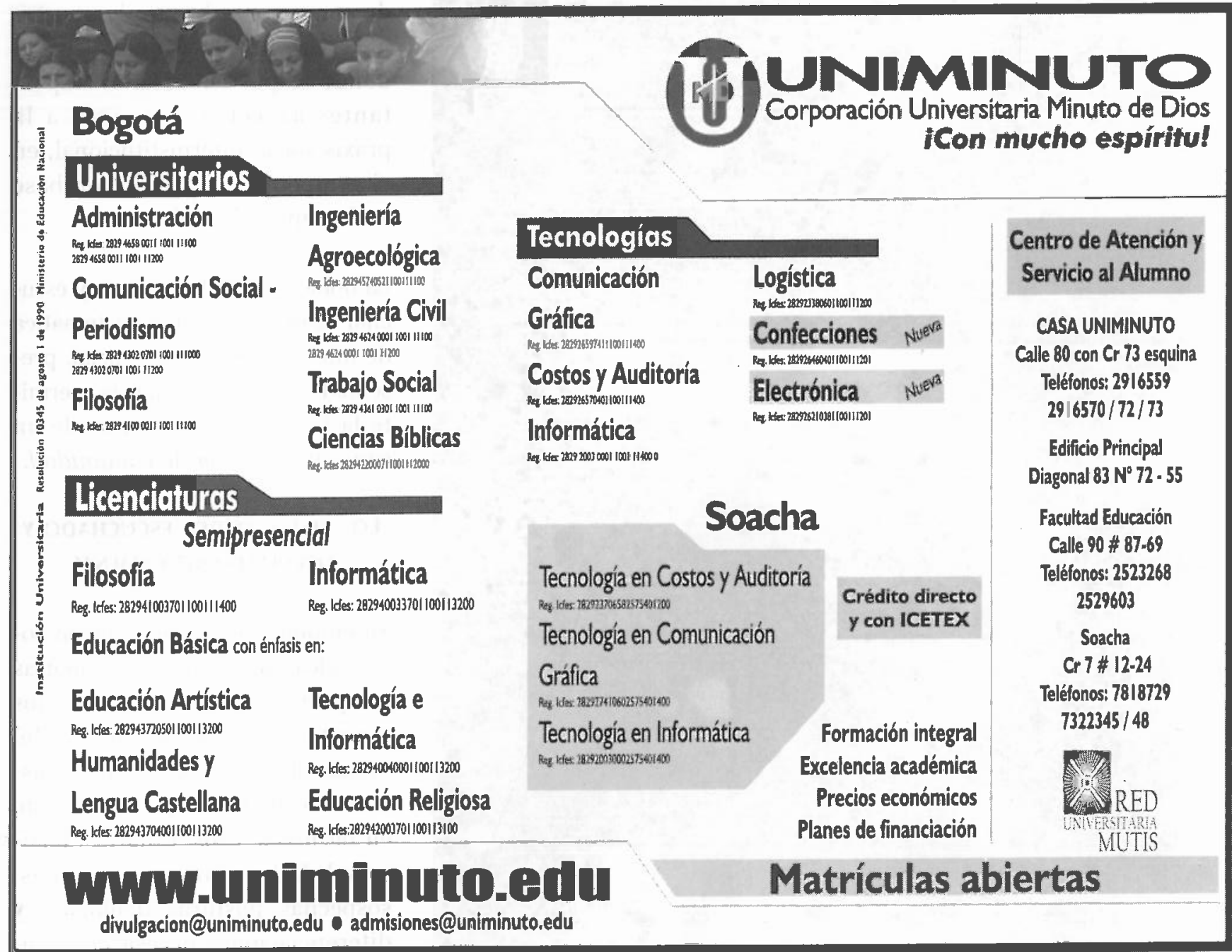

